\title{
A GUIDE AND BEHAVIORAL ANALYSIS TO COMMENCING PUBLICATION OF A PERIODICAL
}

\author{
W. Joseph Wyatt \\ Marshall University
}

\begin{abstract}
A number of steps that must be accomplished to initiate publication of a periodical are presented. The reinforcers and costs of each are discussed. Application and development of these steps in production of a newsletter, Behavior Analysis Digest, are articulated.
\end{abstract}

If it has occurred to you to initiate a journal or newsletter, there may be others with similar interests who might agree. A periodical could be welcomed. The time may be right.

This article will give you some practical suggestions about how, or whether, to proceed. I have organized the following suggestions around a series of questions which could function as a checklist. These questions are general and serve only as an outline, or skeleton, of procedures. To put some flesh on the bones, questions are followed by a description of the Behavior Analysis Digest (Wyatt, 1995) experience.

Skinner (1953) articulated the differences between rule governed and contingency shaped behavior. In developing Behavior Analysis Digest, much of my activity was contingency shaped. That is, I came into direct contact with the contingencies of both reinforcement and punishment for initiating a periodical. I learned by doing, as I learned to ride a bicycle. Now that I have my balance, I hope the reader's behavior will be shaped less by contingencies (especially the aversive ones) and, instead, will come under control of the suggestions contained herein.

\section{Questions}

\section{What is the mission of the proposed publication?}

Decide this before proceeding further. If you are unable to determine your mission, it will be next to impossible to accomplish it. Reduce the mission to a 1sentence statement that appears on the masthead (or the first page) and in your advertising. Ask yourself whether your mission statement is likely to function as a discriminative stimulus for reading further or for stopping. If it is the latter, keep rewriting, perhaps with input from others.

\section{AUTHOR'S NOTE:}

Special thanks to my set-up artist, Terry Erwin, and to $B A D$ 's original set-up person, Mark Foster. Send reprint requests to: W. Joseph Wyatt, Department of Psychology, Marshall University, 400 Hal Greer Blvd., Huntington, WV 25755. For a free sample issue, or for more information about Behavior Analysis Digest write to: W. Joseph Wyatt, Editor, P.O. Box 844, Hurricane, WV 25526. 


\section{WYATT}

\section{Is there a need for this publication?}

Will its reinforcement value outweigh its costs to the readership? Is it possible that you are dangerously close to duplicating an existing publication? Are you accurately estimating the potential interest? Obtain input from those you trust and allow that input to guide you.

\section{Who will subscribe?}

Is there a ready-made readership, such as the membership of an interest group or organization? If so, can you obtain its mailing list? You probably will have to pay for the list, but it is very likely worth the cost. Why fail simply because nobody knew?

Examine the pool of potential subscribers from several perspectives. If your periodical is moderately to highly technical it will appeal to a professional audience. If it is only mildly technical, or non-technical, it may interest a much broader group (e.g., professionals in related fields), or perhaps some segments of the general public. Libraries and agencies may be persuaded to subscribe if even a single individual requests that they do so.

\section{What will be the writing style?}

The style continuum ranges from "highly technical" to "newspaper." Decide where you want to be on this continuum. The location you select will depend largely on your identified readership.

If you are (as I suspect) a trained professional, you may find it difficult to write in newspaper style; however, the more technical your writing, the smaller may be your potential subscriber list. What good comes from a publication that ceased to exist because too few readers understood it?

\section{Who will do the writing and editing?}

The reinforcers for authorship and membership on an editorial staff, or board, are self-evident. These activities may advance the careers of the writers and board members, and contribute to a better society.

An editor-in-chief is crucial, and must be a person who is highly dedicated, knowledgeable, organized and willing to subjugate other reinforcers to those resulting from being editor. In other words, there is a high probability that you will be the editor-in-chief.

The probability of having an article submitted for publication increases with the author's perception of the likelihood that it will be accepted by the editor. Invite respected writers with relevant expertise to write an article. One or two of these in each of the first few issues can help establish your publication's reputation as valued source of information.

Recruit editorial board or staff members from among those whose interests parallel your mission statement. When you approach them, delineate their editorial responsibilities clearly (e.g., editing three papers per year). 


\section{COMMENCING PUBLICATION}

6. Will the publication be biannual, quarterly or monthly?

If monthly, you will probably have to quit your job and say goodby to all other professional activities for as long as you are in charge. If quarterly, or twice yearly, other activities are possible.

\section{What will be the physical appearance of the newsletter or journal?}

This is important for one reason: The potential subscriber's initial glance must be reinforced. This glance will last about $5 \mathrm{~s}$, and, if reinforced, the reader may scan the rest of the cover. Then he or she may turn it over and explore the back cover. If that is reinforced, a title or headline will be read, then the first line of an article or two. If reading those is reinforced, you may have recruited a new subscriber. This takes only 1-2 min, a small cost to the reader, but as much time as most are willing to invest before making a decision. Make the minute count.

\section{What will the title be?}

It should be short and descriptive. If possible, it should make for a good acronym. It should lead the reader to scan the mission statement or some other material on the cover or page 1. Suppose, for example, a newsletter is intended for mechanical engineers. A title such as Mechanical Engineering Quarterly tells you the basics, and has an appealing acronym. Take your time selecting a title. A poor choice can hurt sales, confuse readers and decrease probability of reader acceptance.

\section{What are the mechanics of production?}

Once you have a supply of articles edited, what must be done to get the finished publication into the hands of your readers? Unless you are an expert in desk-top publishing, you will need a professional to make an initial copy of the issue (called a galley). Shop around, as prices for publication set-up vary substantially.

Next comes printing. A basic rule of thumb is that cost per copy to you becomes less as the number of copies increases. For instance, it may cost only an additional $15 \%$ to have 500 copies versus 250 copies printed. Again, compare prices for printing.

You need an individual to handle your mailing list: Keeping it updated as new subscriptions are purchased, sending renewal notices to those whose subscriptions are about to expire, affixing postage, staffing envelopes, etc. You may pay a professional organization or, for a relatively small subscription list, you can do it yourself. With more than 500 subscribers it may be better done by a professional mailing company.

Should you mail via bulk rate or regular first class? You save very little using bulk rates for less than 300 pieces; also bulk rates require pre-sorting by zip code order, an additional job for you.

\section{What about "hidden costs"?}

You will have phone calls to authors and subscribers, letterhead stationary (better if it is similar in form to your cover or masthead), and you may want to do some advertising. Set up a checking account apart from your personal account through which all periodical-related money is channeled. 


\section{WYATT}

\section{What are the reinforcers?}

To know that your periodical is having an impact is a powerful incentive to keep going, as is each renewal and new subscription. Readers' personal comments, letters, and notes scribbled on their renewal notices are nice, too.

This feedback may have to suffice in lieu of financial rewards, unless you anticipate publishing a genuine mass-market periodical that will be purchased by tens of thousands of readers.

\section{Flesh on the Bones}

\section{The Behavior Analysis Digest Experience}

Behavior analysis is a field that is unknown to some and often misrepresented to [and by] others (Todd \& Morris, 1983; Wyatt \& Newman, 1993).

Occasions present themselves in which it seems that the most productive course is to provide an individual with non-technical behavior analytic literature. It would be nice to say, "Here, read this. It will show you some of the things behavior analysis is about."

Thus, an idea for a newsletter was born. After some tinkering, a mission statement was developed.

Behavior Analysis Digest is an international digest to provide a clearing house and exchange of concise news and information on the experimental, theoretical, and applied analysis of behavior.

This would be a newsletter easily shared with others, including both those who have little knowledge of the field and those who misperceive it. It would be contemporary, provide news in digest form, and would provide broad coverage of the field.

Was there a need for such a publication? Experience suggested that there was. Conversations with many colleagues suggested the need for a newsletter that could communicate the richness of our discipline and make clear its pragmatic approach to problem solving. If handed to a student, classroom teacher, social worker, administrator, or other individual who was not a behavior analyst, it should inform with no other support.

Who would subscribe? The membership list of the Association for Behavior Analysis-International was purchased. The first issue, with a subscription form, was sent to each member. Back issues, with order forms, were distributed at the "FreeTake One" table at the annual conference of the same organization.

Over time, distribution to secondary readers occurred. Subscribers reported that they shared articles and entire issues with interested individuals. To this extent, the project is a success.

On the "technical-to-newspaper" style continuum, Behavior Analysis Digest lies near the "newspaper" end. This is consistent with the newletter's mission of communicating behavior analysis to those not technically trained. We encountered a problem because writing in newspaper style is unnatural to those who usually write technically. Gradually, however, the writing evolved toward that recommended by those who write for the popular media (Chance, 1991). The style uses short sentences and short paragraphs, little or no jargon, the active rather than passive voice, avoids 


\section{COMMENCING PUBLICATION}

most unnecessary qualifiers (extremely difficult for trained researchers) such as "may" and "tends to," and others.

Several behavior analysts agreed to serve on the first editorial board and to write articles for the first few issues. In time, others contributed articles, including students who got their first publication in Behavior Analysis Digest.

The editorship fell to me as the one who had determined the newsletter's mission and was willing to commit the time necessary.

Production of the first issue took an estimated 80 hours. It cost approximately $\$ 1,000$ out-of-pocket to produce and mail free samples of that issue. As subscriptions approached, then passed, the number needed to break even, my efforts were reinforced. The Digest became a quarterly publication. Time and money precluded monthly issues. Less frequent publication seemed insufficient.

The physical appearance of page 1 includes a masthead with the title and mission statement. A one-sentence definition of behavior analysis runs across the bottom of the page. Page one usually contains three articles, each continued on the inside. Titles are in "headline" style, followed by author, author's affiliation and a dateline.

This title appears on a cover article in a recent (Fall, 1994) issue. "Strides made in conversational skills for schizophrenics" (Wyatt, 1994). This is more informative to the non-professional reader than the original article's title, "Conversational skills training with schizophrenic inpatients: A study of generalization across settings and conversants" (Wong, et al., 1993). The newspaper-like title is understandable to the non-behavior analyst and serves as a discriminative stimulus for reading further.

The newsletter's title, Behavior Analysis Digest, is short, says that behavior analysis is the topic, and that articles are in abbreviated form. Its acronym, $B A D$, is easy to remember. This can, however, lead to some malapropisms as in, "I just read a $B A D$ article that was good."

Production of Behavior Analysis Digest begins with receipt, review and editing of articles. Then a typist/set-up person creates the original which is printed locally. This takes about 30 days.

The typist also updates the mailing list and produces stick-on mailing labels. I pay by the piece to have the envelopes addressed, stamped and stuffed. For subscriptions that are expiring, renewal notices and return envelopes are enclosed. The business address is a post office box.

Several students have served on the Board of Editors. Others have been encouraged to contribute by faculty members who serve on the board. Janet Ellis' students at the University of North Texas have been especially productive. Preparing a submission to $B A D$ is part of a course requirement and students, in turn, have at least one publication for their resumes upon graduation. Several articles have come from the students of M. Michelle Burdette and Robert P. Hawkins at West Virginia University.

\section{Conclusions}

Several ingredients are necessary to publish a periodical. These include a mission, an existing need for the publication, subscribers, a plan for the writing style and frequency of publication, those who will submit and edit articles, an editor-in- 


\section{WYATT}

chief, a reinforcing physical design, and a descriptive title. Production needs include typing, set-up of an original issue, printing, mailing, updating of the subscribers list, and a checking account.

Advertising can be costly, though inexpensive options are available. One of these is distribution of free samples (back issues) at conferences. Another is a liberal reprint policy. Finally, $B A D$ encourages reprinting of its articles. It requires only that the statement, "Reprinted with permission of Behavior Analysis Digest," appear at the end of each.

\section{REFERENCES}

Chance, P. (1991, May). Media relations for behavior analysts. Workshop presented at the meeting of the Association for Behavior Analysis International, Atlanta, GA.

Skinner, B.F. (1953). Science and Human Behavior. New York: Macmillan.

Todd, J.T., \& Morris, E.K. (1983). Misconceptions and miseducation: Presentations of radical behaviorism in psychology textbooks. The Behavior Analyst, 6, 153-160.

Wong, S.E., Martinez-Diaz, J.A., Massel, H.K., Edelstein, B.A., Wiegand, W., Bowen, L., Liberman, R.P. (1993). Conversational skills training with schizophrenic inpatients: A study of generalization across settings and conversants. Behavior Therapy, 24, 285-304. http://dx.doi.org/10.1016/S0005-7894(05)80270-9

Wyatt, W.J., \& Newman, B. (Chairs) (1993, May). Killing us softly: Representations and misrepresentations of behavior analysis in popular introductory psychology texts. Symposium conducted at the meeting of the Association for Behavior Analysis-International, Chicago.

Wyatt, W.J. (Ed.). (1995). Behavior Analysis Digest, (7,1).

Wyatt, W.J. (1994). Strides made in conversational skills for schizophrenics. Behavior Analysis Digest, 6, 9-11. 